\title{
Frequency Domain Observations of Small Motions at Concrete/Steel Interfaces
}

Brian P. Bonner

$\therefore$ OEVED

Alfs 201996

OSTI

June 1996

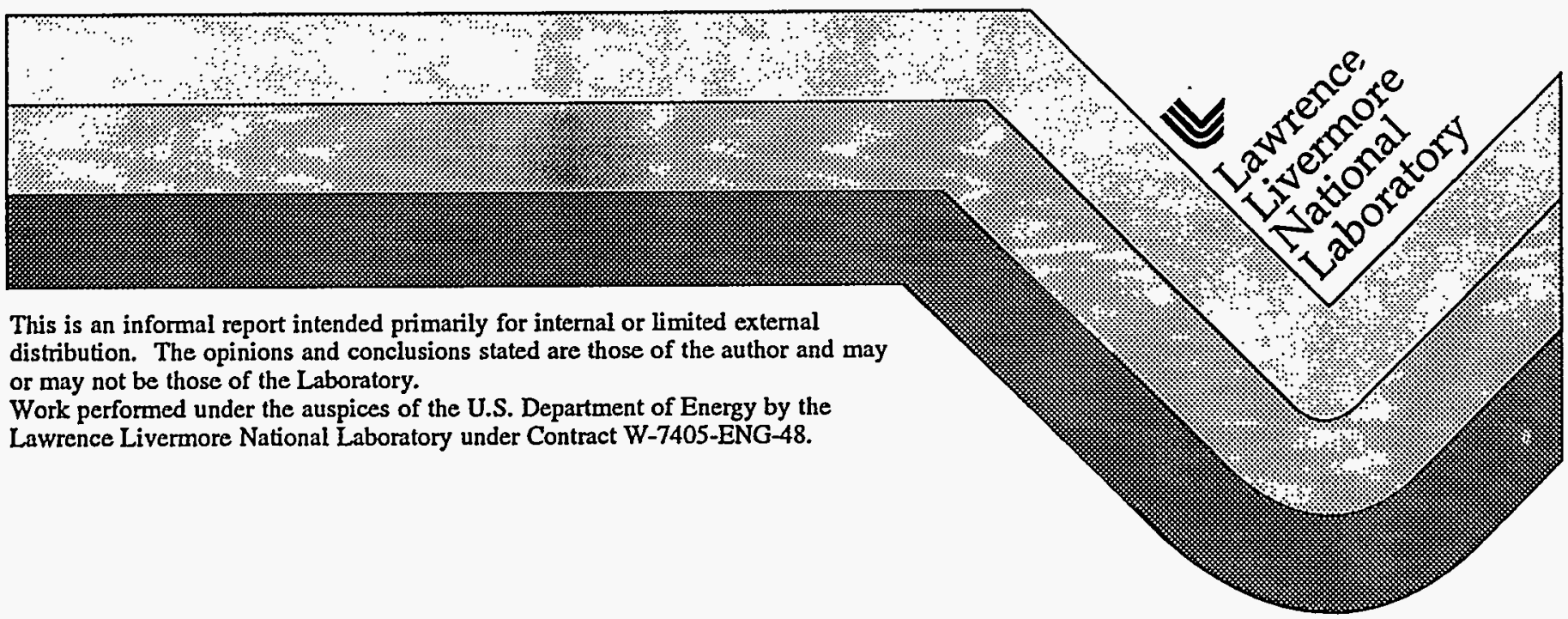




\section{DISCLAIMER}

This document was prepared as an account of work sponsored by an agency of the United States Government. Neither the United States Government nor the University of California nor any of their employees, makes any warranty, express or implied, or assumes any legal liability or responsibility for the accuracy, completeness, or usefulness of any information, apparatus, product, or process disclosed, or represents that its use would not infringe privately owned rights. Reference herein to any specific commercial product, process, or service by trade name, trademark, manufacturer, or otherwise, does not necessarily constitute or imply its endorsement, recommendation, or favoring by the United States Government or the University of California. The views and opinions of authors expressed herein do not necessarily state or reflect those of the United States Government or the University of California, and shall not be used for advertising or product endorsement purposes.

This report has been reproduced directly from the best available copy.

Available to DOE and DOE contractors from the Office of Scientific and Technical Information

P.O. Box 62, Oak Ridge, TN 37831

Prices available from (615) 576-8401, FTS 626-8401

Available to the public from the

National Technical Information Service

U.S. Department of Commerce

5285 Port Royal Rd.

Springfield, VA 22161 


\section{DISCLAIMER}

Portions of this document may be illegible in electronic image products. Images are produced from the best available original document. 
Frequency Domain Observations of Small Motions at Concrete/Steel Interfaces

Brian P. Bonner

Geophysics and Global Security

Lawrence Livermore National Laboratory

Submitted to:

Review of Progress in Quantitative Nondestructive Evaluation

When two rough interfaces in contact are driven in harmonic motion, the frictional resistance to shear causes the response of the driven system to be nonlinear. The displacement along the interface cannot be described by a linear predictor, one analogous to Hooke's law for elastic response. Experiments'conducted under laboratory conditions are described here to illustrate that the resulting motion is not random, but produces measurable and characteristic output at harmonics of the driving frequency. Although the geometry of the tests described here is not practical for evaluating the integrity of steel/concrete interfaces in structures; the results illustrate that the principle should apply to other geometries where shearing forces can be applied to interfaces to determine the quality of bonding.

\section{Experimental Apparatus and Procedure}

The harmonic torsional oscillator used for studying friction on steel/concrete interfaces has already been used successfully for a variety of applications in the shear testing of natural and manufactured materials. A schematic representation of the testing machine is shown as Figure 1. A description of the design and operation of the oscillator with application to measurements in fractured rock appears in Bonner and Wanamaker ${ }^{1}$, so only a brief overview will be given here. This oscillator been used primarily to determine modulus and attenuation for rocks and is similar conceptually to devices commonly used in polymer rheology 2 . A unique feature of the apparatus is it's ability to apply uniaxial loads along the symmetry axis of the sample to investigate the effect of normal stress. The oscillator operates at frequencies between 0.01 and $100 \mathrm{~Hz}$ at strains ranging from $10^{-7}$ to $10^{-4}$. Samples are twisted by supplying a sinusoidal voltage to the electromagnetic assembly which drives an array of permanent magnets attached to the sample column. Displacements are measured by eddy current proximity detectors which determine the motion of arms extending from the torsion column on either side of the sample. Displacements nearer to the fixed end depend only on the elastic deformation of the aluminum torsion bar and are proportional to torque. Displacements measured on the other side of the sample are proportional to sample strain. By taking the complex ratio of displacement time histories for the two sensor positions along the torsion rod assembly, we can compute the shear modulus, shear attenuation and harmonic distortion as a function of amplitude. By measuring the distortion of the sinusoidal input introduced into the output, we can characterize the nonlinear component of sample response. Nonlinear effects occur preferentially in the high strain region, which is nearest to the outside surface of the composite cylinder. The apparent contribution of the apparatus to sample response is determined by comparative measurements with aluminum alloy and polyvinyl chloride samples, which have linear rheologies and known stiffness and attenuation. 
Special composite samples were prepared for this study. These samples were segmented rods, half concrete and half steel. Concrete specimens (which are technically mortar, because no large aggregate was used) were prepared following standard ASCE practice. Small rods of $\sim 9 \mathrm{~mm}$ diameter were cut from large blocks using diamond coring drills. Segments of standard reinforcing bar, with a nominal diameter of $12.5 \mathrm{~mm}$ were machined to fit into the grips of the testing machine. The other end of the rebar was machined flat and then peened to produce an irregular surface with relief of $\sim 0.5 \mathrm{~mm}$. The concrete and steel segments were held together during testing by normal forces applied by a spring loading system, as described above.

\section{Results}

A series of tests were performed to quantify the effect of drive amplitude and normal stress, the parameters that control interface response. The basic procedure is to measure interface shear stiffness, attenuation, and input distortion as a function of drive amplitude for different values of the normal force applied normal to shear. The essential nonlinear character of the response is clearly evident in results for an $8 \mathrm{~Hz}$ driving frequency with $\sim 13 \mathrm{~kg}$ normal load. Attenuation and harmonic distortion of the sinusoidal input are plotted as a function of drive amplitude in Figure 3. The phase lag between torque and sample twist, which determines the loss at $8 \mathrm{~Hz}$; increases by over $300 \%$. The harmonic distortion, which is a measure of the power transferred mainly into the first five harmonics, also increases over 300\%. Although increases in stiffness (not shown) are not as dramatic, this too is consistent with important nonlinear response.

Transforming the sample output time series into the frequency domain provides the most effective method for separating and making quantitative measurements of the nonlinear response. The sample response in $\mathrm{dB}$, for constant drive amplitude with two different normal loads, is plotted as a function of frequency in Figure 4. More power is transferred into the odd harmonic, suggesting that the sinusoidal input is being distorted into a triangular shape. Changes in the normal load, which do not appreciably alter the response at the fundamental frequency of $2 \mathrm{~Hz}$, clearly increase the harmonic content. Decreasing the normal load causes easily detectable increases; power in the second harmonic increases $-3 \mathrm{~dB}$ (corresponding to an increase of power of $200 \%$ ) with a $2 \mathrm{~kg}$ decrease in load. Identical measurements performed for samples of concrete, without an interface, demonstrate that this nonlinear effect does not arise in the concrete matrix.

\section{Discussion}

Frictional sliding on interfaces is important for a wide range of applications, and previous analysis of the problem provides guidance for understanding the response of the steel-concrete interface response. When two rounded surfaces in contact are sheared while simultaneously under the action of a normal force, a singularity in shear traction develops at the boundary of the contact area ${ }^{3}$. Since a real material cannot support the singularity, it must be relieved either by local plastic flow or by partial slip. Some slip must occur on favorably oriented subareas of any rough surface, even at arbitrarily small shearing stress. However, displacements associated with this process approach zero in the limit as shear stress is reduced, and it becomes increasingly difficult to separate partial slip from the elastic deformation of the interface region. As has been demonstrated here, harmonic excitation of the rough surface combined with frequency domain analysis of the response, provides 
a solution to this problem. The motion along the interface is not random, but includes measurable and characteristic output at harmonics of the driving frequency. This behavior is consistent with observations of a wide variety of mechanical and electrical nonlinear systems ${ }^{4}$. Although the torsional geometry used here is not easily applied for evaluating the integrity of steel-concrete interfaces in engineered structures, the principle should apply to other geometries designed to measure the response to shearing forces. Partial slip can be detected at low levels to evaluate interface quality and the integrity of bonding.

\section{Acknowledgments}

Chantel Aracne-Ruddle provided excellent technical support throughout this study. This work was supported by an award from the LLNL Lab Wide LDRD Program and was performed under the auspices of the US. Department of Energy by the Lawrence Livermore National Laboratory under contract number W-7405-ENG-48.

\section{References}

1. B. P. Bonner and B. J. Wanamaker, in Review of Progress in Quantitative NDE, edited by D.O. Thompson and D.E. Chimenti, Plenum.Press, New York and London, (1991) Vol. 10B, p. 1861.

2. J. D. Ferry, Viscoelastic Properties of Polymers, Wiley, New York, (1980).

3. R. D. Mindlin and H. Deresiewicz, J. Appl. Mech., 75, 327, (1953).

4. J. J. Stoker, Nonlinear vibrations in mechanical and electrical systems, Interscience Publishers, New York, (1950). 


\section{Figure Captions}

Figure 1: Schematic representation of the harmonic torsional oscillator used for tests. The entire apparatus is about $75 \mathrm{~cm}$ long. Samples are cylinders, $9 \times 50 \mathrm{~mm}$. The samples in this case are segmented roughly into equal parts of prepared rebar and mortar, separated by an interface. The interface can be loaded by normal force applied along the symmetry axis of the apparatus.

Figure 2. Sample configuration used to study interface motion. Steel surfaces are first machined flat to produce a reproducible starting condition and then roughened to create a geometry favorable for partial slip.

Figure 3. Attenuation and distortion of input vibration caused by partial slip at the interface. The phase lag between excitation and response measured at the driving frequency is plotted on the left ordinate and the total harmonic distortion (as defined in the text) is plotted on the right. Both increase with excitation amplitude.

Figure 4. Output power spectra for driven oscillations of the composite sample. Energy is transferred to higher harmonics of the driving frequency by nonlinear sample response. Measurements for two different uniaxial loads show the effect of partial slip on harmonic content. 


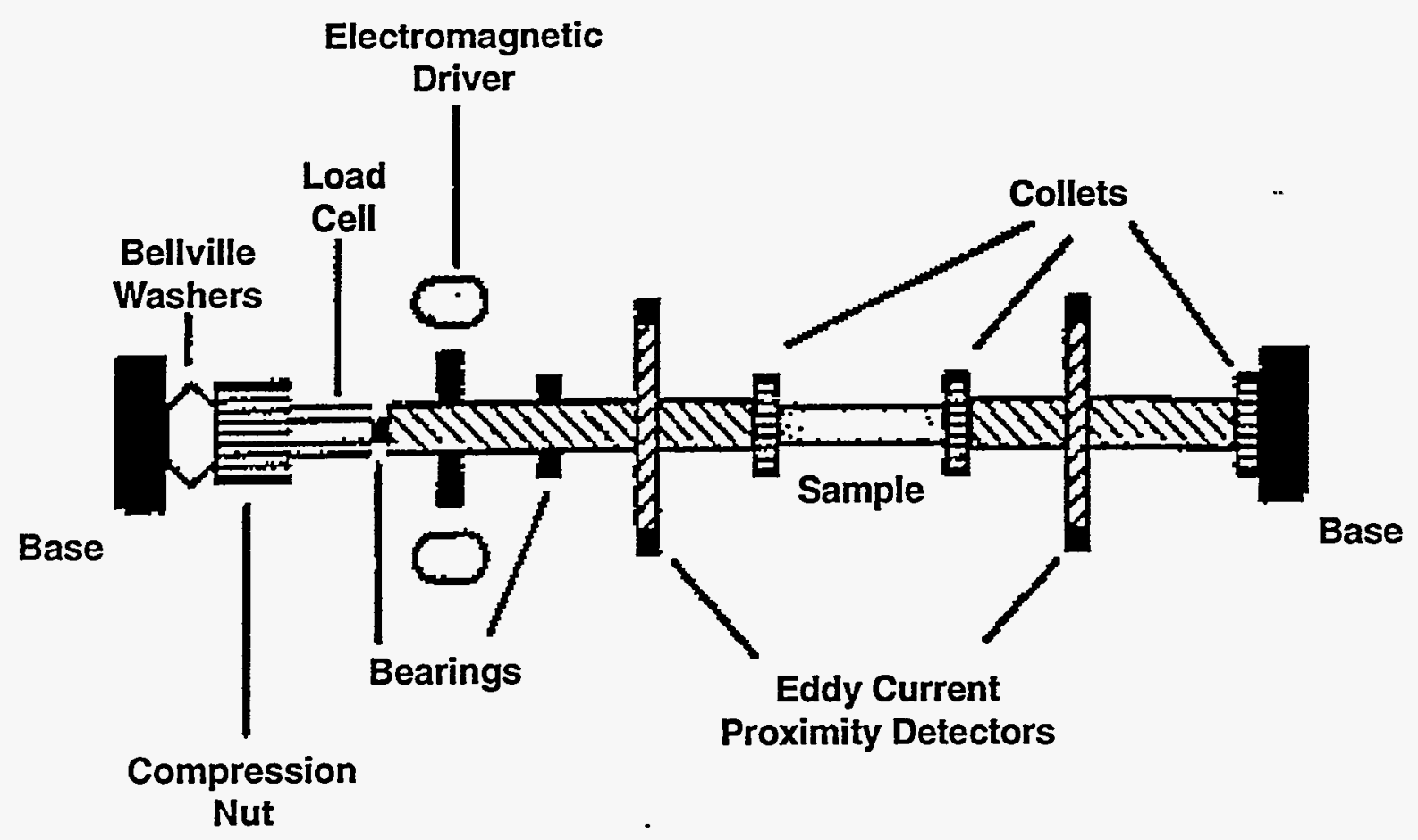

TORSIONAL OSCILLATOR

Figure 1 


\section{TEST GEOMETRY:}

\section{Torsion Test}

Normal Stress
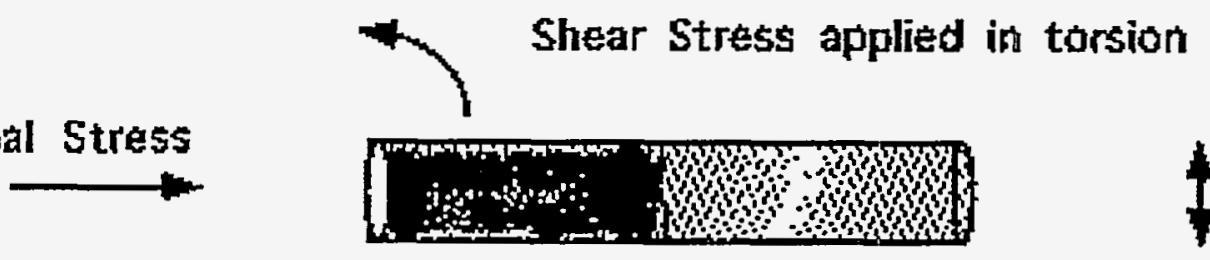

$\$ 9 \mathrm{~mm}$

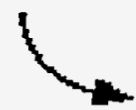

Normal Stress controls the amount of partial slip

Figure 2

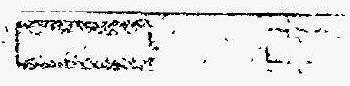




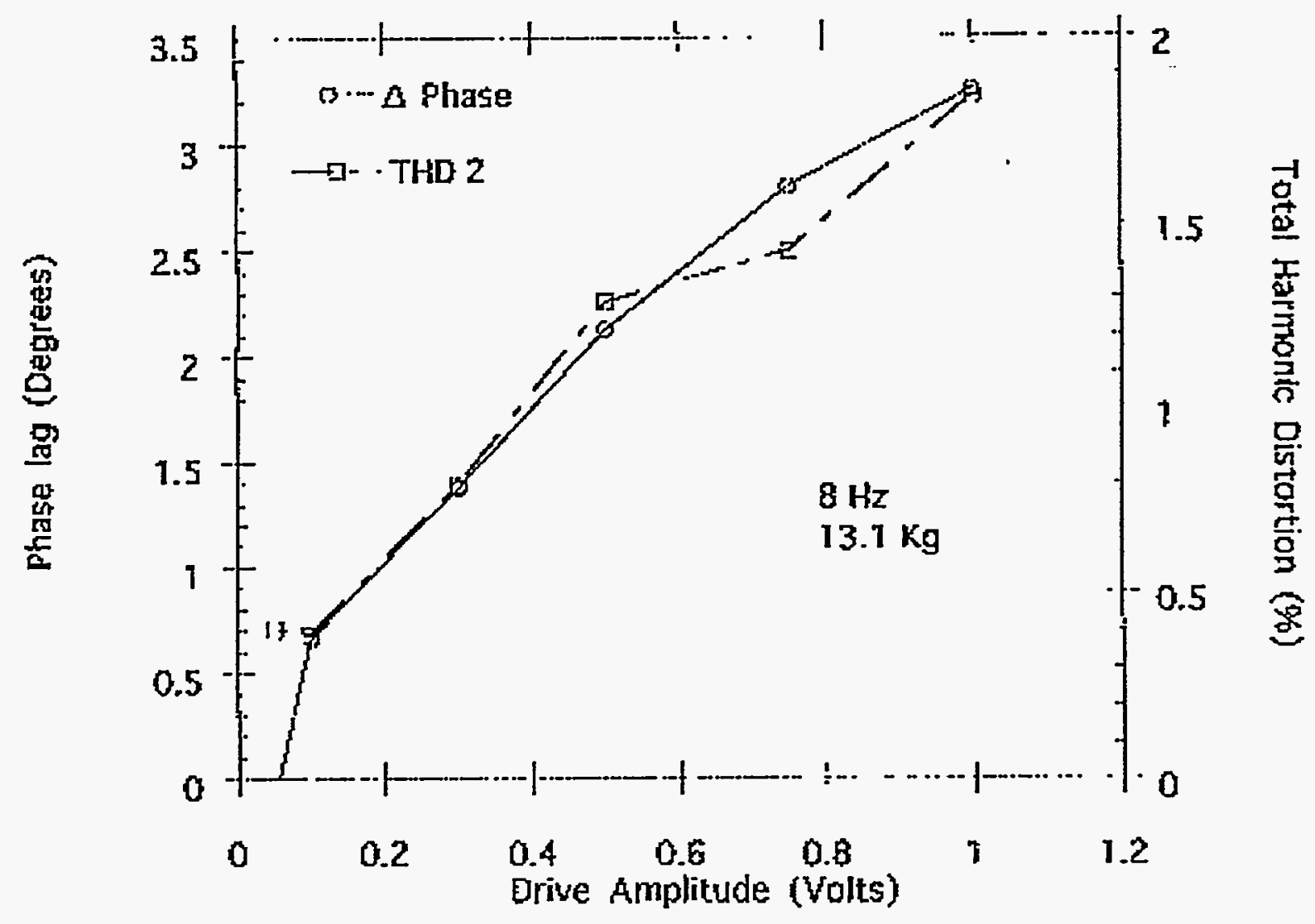

Figure 3 


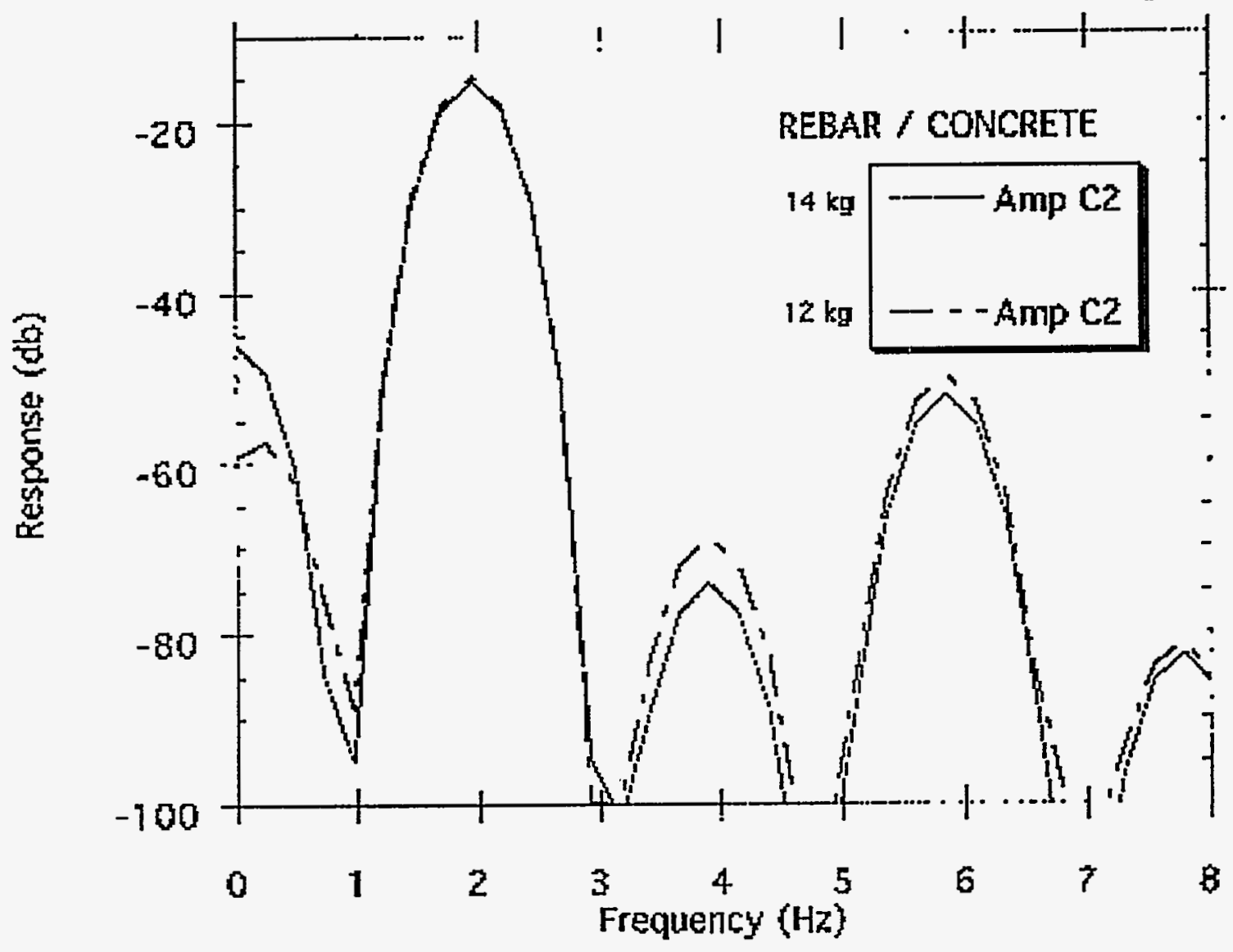

Figure 4 

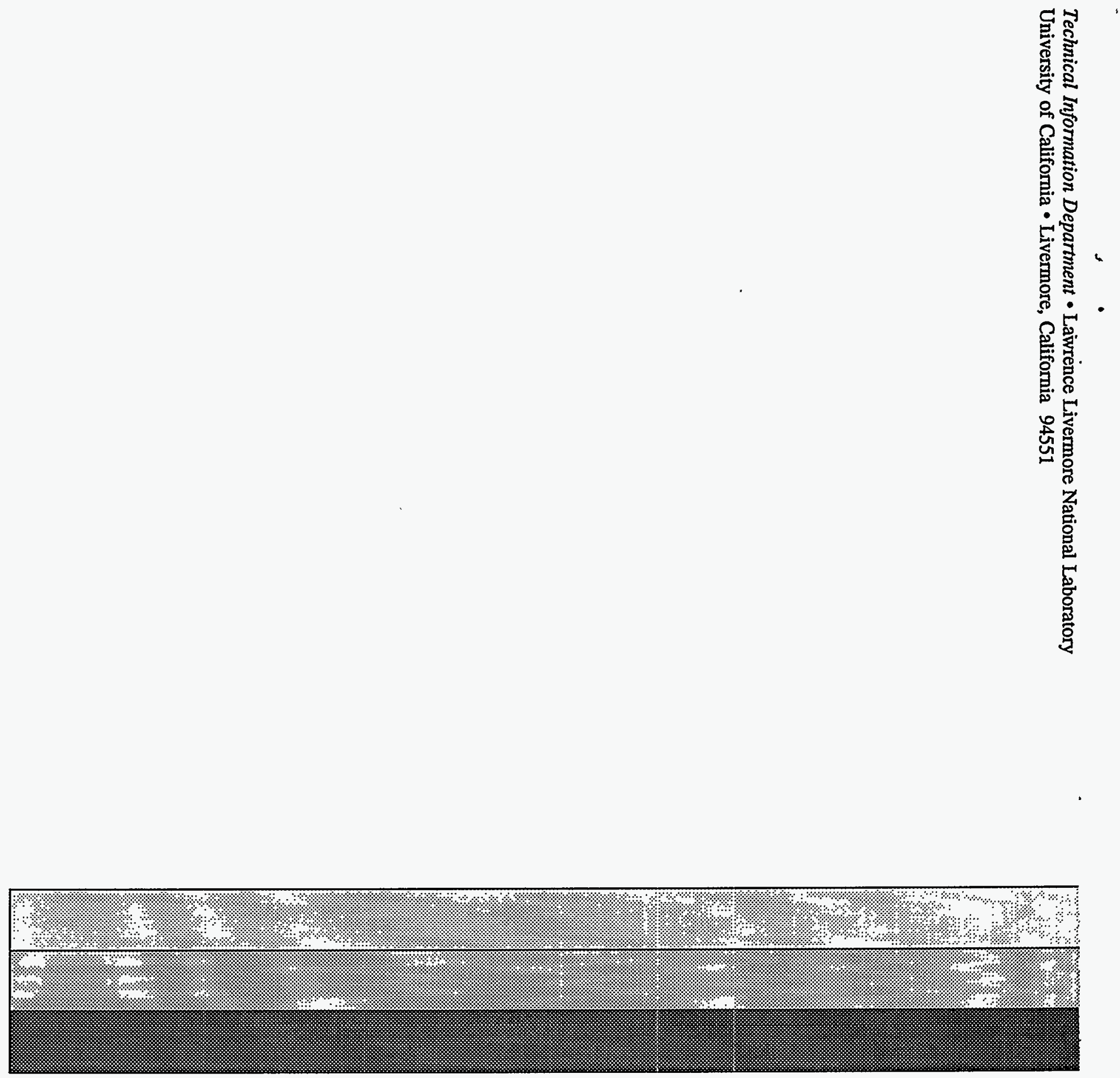